\title{
Levantamientos Campesinos en El Salvador
}

\author{
Segundo Montes
}

\section{Introducclón}

El presente articulo es parte de un trabajo más extenso preparado para una publicación conjunta sobre este problema en los diferentes países de la región, que eslá edilando una universidad norteamericana. Se da por supuesto y conocido para este trabajo lo ya escrito por mi anteriormente sobre la tierra, el campesinado, las reformas y revoluciones agrarias, la lucha por el único recurso natural y las consiguientes convulsiones y crisis políticas que se han derivado de cada fase y tipo de cultivo predominante, pero no se lo incluye en este artículo para no repetirlo (Montes, 1986 a; 1986 b; 1987).

Por consiguientes, me voy a restringir a una descripción de los divesos levantamientos y revoluciones campesinos ocurridos en la historia independiente de EI Salvador, aunque dará más extensión y énlasis a la presente, no sólo porque era el objeto principal del Irabajo aludido, sino porque hay más datos, más estudios y más evidencias individuales y colectivas sobre la crisis y la guerra civil presenles. En la segunda parte Irataré de elaborar una interpretación teórica sobre dichos movimientos, a fin de categorizarlos y extraer principios y conclusiones que ayuden a entenderlos $-y$ tal vez colaborar a solucionarbs.

\section{Levantamlentos campesInos en El Salvador.}

En El Salvador se han producido tres grandes alzamienlos campesinos, aunque de muy diversa Indole y en épocas muy diferentes. Ya en los anteriores y cilados trabajos se ha hecho relerencia a los mismos, y a las crisis derivadas de cada uno de los períodos de producción agraria para el mercado internacional, por lo que no amerita extenderse demasiado sino describir sucintamente los primeros y más a fondo el actual. 


\section{A. El levantamiento de 1833.}

Del primer levantamiento, liderado por Anastasio Aquino, "capitán

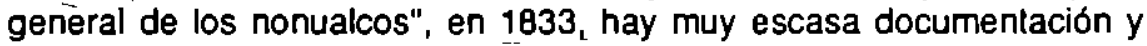
estudio histórico sistemático, dada la época, la crisis generalizada en la región, y el bajo nivel científico en incluso inlelectual de enlonces. El me: jor y más sistemático que conozco es el de Jorge Arias Gómez, titulado "Anastasio Aquino, recuerdo, valoración y presencia" (Arias Gómez, 1964). Las condiciones económicas del país, de Centroamérica -todavía unida-, y de la región, asi como las constantes guerras y luchas intestinas y regionales, crearon una situación intolerable en la población nonualca, que trabaja lambién en las fincas an̂ileras, tanlo por la dificultad de reproducir su vida, como por las constantes levas a las que somelian a los jóvenes para luchas en los diversos ejércitos de los ladinos; incluso el maltrato físico y la tortura a uno de sus hermanos, le movió a Aquino a movilizar a su genle para que no fueran reclulados para el ejército ni forzados a trabajar en las fincas o haciendas de ladinos, lo que motivaria una serie de acciones de defensa contra los intentos gubernamentales, y la configuración de un ejército propio nusticamente armado para luchar y ampliar su campo de autonomía. Incluso parece ser que se tomó ciudad de San Vicente, y se duda si se coronó en la iglesia, con la corona y manto de San José, como "rey de los nonualcos". Posiblemente la leyenda pudo ser creada por los ladinos mismos de San Vicente, que se habian refugiado en la iglesia, con lodo lo que pudieron llevarse consigo, confiando en que los indígenas no se atreverían a "profanar el templo", asi como para juslificar ideológicamente la represión y casi exterminio que aplicarian a Aquino y a los nonualcos después de la caplura y derrola, mediada primero por un sacerdole intermediaro enviado por el gobierno -que no sólo conversó con Aquino, sino también tomó observaciones y datos que luego servirian para atacar los puntos débiles-, y después por la Iraición comprada de su lugarteniente y ayudante supuestamente más fiel (Arias Gómez, o.c.).

\section{B. El levartamiemo de 1932.}

Sobre el levantamiento campesino de 1932, en la zona occidental del país - la zona de los izalcos-, se ha escrito e investigado bastante, no sólo por ser en época más reciente, sino también por la reacción internacional trente a la masacre y elnocidio. La crisis mundial de finales de la década de los 20 y comienzos de los 30 provocaría un derrumbe de los precios de los productos de exportación salvadorenos, principalmente el café, que se cultivaba en forma intensiva en la región occidental, de modo que los campesinos vivían en una situación de miseria insoportable, que motivaba continuas manifeslaciones, protestas y actos de represión gubernamental en el occidente del pais -a lo que habia que 
agregar la presión de los izalcos, dirigidos por su lider José Feliciano Ama, por recuperar cierta autonomia local económica, política y cullural-. Las condiciones eran tales que habia manifestaciones y levantamientos espóntaneos disgregados, frenle a los que el gobierno civil de Arturo Araujo no podía hacer frenle ni dar soluciones, y que molivaría el golpe de eslado que llevaría al poder al general Maximiliano Hernández Martinez (Dalton, 1972).

Anderson estudiaria posleriormenle el levanlarniento y su represión en el libro titulado en el original Matanza (Anderson, 1976), y que se convertíria en el libro clásico para el estudio del suceso con todo su entorno $y$ consecuencias.

Yo mismo he esludiado el levantamiento, con trabajo de campo en la zona, entrevista con sobrevivientes de ambas tacciones, como la profundización posible en el afio 1975-76, a tal distancia de tiempo y frente a la resistencia persitente de revivir el problema y habla de ello (Montes, 1979;177-200). En primer lugar, Irato de probar que no fue un "levantamiento comunista" - como le han dado en llamar las fuerzas sociales tradicionales y dominanles, presumiblemente también, como en el caso de Aquino, justificar e intentar legitimar la represión y masacre de posiblemente 30,000 personas (pero que suponiendjo que nada más hubieran asesinado a 10,000 en los cuatro municipios tomados por los campesinos alzados, representaría el $28.55 \%$ de la población de los mismos en esa fecha) - ; a mi criterio fue un levantamiento campesino, cassi_esponláneo, aunque tenia ya un incipiente y débil componente ideológico del partido comunisla en formación, que pretendió hegemonizar è proceso, pero no lograba ni siquiera controlar, mucho menos dirigir a las masas que se alzaban continuamente; y también hay que anadir el componente indigena bajo el liderazgo de Ama, quien aunque luvo conversaciones y posible alianza con los dirigentes del partido comunista en tormación, para apoyar la candidalura del alcalde propueslo por aquél, así como a incitar a su pueblo a la insurrección, sin embargo estaba motivado más bien por su elnia y buscaba los inlereses propios de su comunidad indígena.

La iglesia católica no jugó ningún papel en el levantamiento, dada la orientación tradicional y conservadora prevaleciente en aquel entonces, ni tampoco existian, que se sepa, movimientos cristianos de base ni sacerdotes comprometidos en la liberación del pueblo, que hubiera podido incidir en dicho movimiento. Sin embargo, "el arzobispo de San Salvador, Mons. Belloso, asustado por las muchas ejecuciones, habló al Presidente de la República, y le arrancó la promesa de que se detendrían las ejecuciones, y desde ese momento se le concedieron mayores facilidades y apoyo a la Iglesia de parte del Gobierno y de las diversas autoridades" (Montes, 1979: 191). Ulteriormente la iglesia organizó una 
misión a nivel nacional, especialmente en la zona del levantamiento y sus alrededores, para predicar la paz, el perdón, la reconciliación y la resignación cristianas, sin ninguna denuncia profética de las masacres ni de la violaciones más elementales a los derechos del hombre, y de los indigenas en concreto (cfr. Cardenal, 1980, para entender el trasiondo eclesial de la época, tanlo de Aquino como de Ama).

\section{La actual revolución campesina.}

A la tercera crisis socio-política, la presente, en primer lugar la denomino "revolución" y no simplemente "levantamiento campesino", como tralaré de explicar más adelante, y especialmenle en la última parte del trabajo; en segundo lugar, le voy a dar un Iratamiento más extenso y prolundo, no sólo por la imporlancia mayor, más presente y generalizada, sino por-que es el lenómeno focal del trabajo que se me pidió para el libro en cuestión: levantamientos campesinos después de la Segunda Guerra Mundial. En consecuencia, analizaré la crisis en tres momentos principales.

\section{a) Antecendentes y preparación..}

El derumbre de la producción anilera, como consecuencia de la producción fabril de colorantes, por un lado generó el fracaso económico de los antiguos cultivadores y beneliciadores del anil; por olro lado dejó la economia del país casi exclusivamente dependiente del café, y el poder económico-político en manos de la nueva oligarquia cafelalera; pero al mismo tiempo hizo que las antiguas tierras afileras - de la mesela central-ya no fueran ni productivas ni codiciables, dando paso a cultivos extensivos de granos básicos y de ganaderia, bien mediante trabajo por colonato, o bien de aparceria o arrrendamiento; los campesinos de esas zonas, por lo tanlo, tenian relativamente fácil acceso al mercado de parcelas, 0 al arrendamiemo de las mismas por cánones tolerables.

Las tierras virgenes y de gran fertilidad por la sedimentación de materiales orgánicos arrastrados de las montańas, de la llanura costera, estaban iniestadas de enlermedades tropicales imposibles de erradicar; debido a ello, nunca habian sido cultivadas ni explotadas, $\theta$ incluso su propiedad no era apetecible a no ser como reserva para el fuluro de parte de inversores arriesgados o previdentes. Asi pues, la gran extensión costera estaba abandonada a la vegetación natural y, a lo más se criaba alli ganado en estado salvaje, del que una parte era recogido periódicamente para llevarlo al mercado; lambién se cultivaban algunos granos básicos en la periferia menos insalubre de la iranja coslera, y había salineras junto al mar..

Los descubrimientos biotécnicos de la guerra y de la post-guerra hicieron posible primero la neutralización y luego casi la extinción de la 
enfermededes tropicales de la cosla; la fumigación aérea y terrestre lueron intensivas y conslantes, de modo que la llanura costera se convirtió en habitable y cultivable. A ello se agregaría el que esas tierra eran muy adecuadas para el cultivo del algodón, y este produclo tenia gran demanda y precios atractivos en el mercado internacional. Comenzó en la década de los cincuenta, y posteriormente, la lucha por la tierra; algunos inversores con visión de futuro se lanzaron a la compra extensiva de tierras poco apetecibles y todavia muy baratas, al desmonte de la selva y de la vegelación natural, a la preparación de la tierra para el cullivo del algodón este nuevo grupo empresarial tenía una visión moderna de producción agrícola, con un fuerte componente de capilal, maquinización de cultivos, dejando casi exclusivamente para el trabajo manual la cosecha.

Como consecuencia, la escasa y dispersa población de la zona tuvo que retirarse a los márgenes de los cultivos; el sistema de colonato no era adecuado, ya que la tierra rendía más en cultivos intensivos y mecanizados; se crearon muy pocos puestos de trabajo permanente; sin embargo, el atractivo de la ocupación de abundanle mano de obra en las cosechas hacia que mucha gente fuera a las misma y una parte de ella se quedara más o menos permanenlemente, a las orillas de los caminos, en lugurios amenazados por la intoxicación de los insecticidas regados por medio de avionetas.

Por otro lado, el triunfo y consolidación de la revolución cubana motivó el que el gobierno norteamericano decretara una ruptura de todo tipo de relaciones con la isla y un bloqueo a la misma. El azúcar -producto principal de Cuba, y que era adquirido casi exclusivamente por el mercado norleamericano - fue excluído, y la cuola cubana de exportación se repartió entre varios paises de la región centroamericana y del Caribe -entre ellos, El Salvador-. Las antiguas tierras anileras, abandonadas duranle décadas, o sometidas a cultivos poco productivos, resultaron ser de muy buena calidad para el cultivo de la cafia de azúcar. En la misma forma que el algodón, la caf́a de azúcar se iba a cultivar con métodos más modernos y mecanizados, ocupando abundante mano de obra en las cosechas, pero muy escasa durante el resto del ano. Por olro lado, las tierras que hasta entonces no eran muy apetecibles se conviertieron en altamente productivas - por la cuola y precios de exportación asegurados-, y su cultivo más rentable que el colonato o cualquier otro medio atrasado de producción. Como consecuencia, los colonos, los arrendatarios pequenos, los aparceros serian excluidos y relegados a las áreas marginales $\theta$ improductivas, $e$ incluso muchos pequefios propietarios venderlan sus parcelas para el cullivo de la cana, ya fuera atraidos por el precio de oferta, ya fuera presionados de alguna forma a ello. 
Los anteriores procesos fueron privando de lierra y de Irabajo a la población campesina en constante y progresivo crecimiento, y no generaban, por el contrario, puestos de trabajo moderno sulicientes para la oferta laboral - como lampoco la ciudad y su proceso de expansión, industrialización y modernización era capaz de absorber la fuerza laboral que llegaba del inlerior, ni de crear la inlraestruclura habitacional y de los demás servicios indispensables para la vida urbana, mucho menos con el Iracaso del mercado común centroamericano-. Finalmente la guerra con Honduras, en julio de 1969, provocarla la repalriación de unos 100,000 salvadorenos, en su inmensa mayorla campesinos que trabajaban alli en el agro, que trataban de retomar a sus lugares de origen, y que incrementaron considerablemente la presión sobre la tierra y sobre el trabajo en el campo, relegando al campesino a condiciones materiales incluso inferiores alas de la población marginal urbana y metropolitana (Montes, 1979a).

La década del 70 , subsiguiente a la guerra con Honduras, la repatriación de esos campesinos, el fracaso del Mercado Común Centroamericano (MCC), el cierre de la frontera hondurena a personas y productos salvadorenos, sería el perlodo de gestación y consolidación del proceso revolucionario, fundamental, pero no exclusivamente, campesino.

A comienzos de la década se forman los primeros grupos guerrilleros, todavla pequenos e incipientes, aislados aún de la base popular, de extracción más bien urbana $e$ intelectual con algunos componentes obreros y sindicales. Pero a media que las condiciones en el campo se vuelven más insoportables, van surgiendo diversas organizaciones campesinas - la sindicalización campesina está de hecho prohibida, y los trabajadores del campo ni son permentes en su mayoría ni gozan de los beneficios sociales básicos: seguro social, indemnización, jubilización etc.-, al principio con carácter puramente reivindicativo y con planteamientos económicos, que serán reprimidas en la mayor parte de los casos, to que llevará a una radicalización mayor en su postura ideológica y en sus alianzas (ECA, 1974: 804-6; 1975:325-8; Cardenal, 1985: 217 300; Studemeister, 1986: 57-59).

FECCAS y UTC (Federación Cristiana de Campesinos Salvadoreños, y Unión de Trabajadores del Campo, respectivamente), que en un comienzo tenian poca base popular, se irian fortaleciendo, para conformar en 1985 la FTC (Federación de Trabajadores del Campo). Si al comienzo no tenlan relación alguna con los grupos guerrilleros, la represión les forzarla al principio a armarse rústicamente para defenderse, luego a una alianza con ellos para su protección, para pasar al final de la década a contormar un vinculo orgánico. 
Las elecciones presidenciales de 1972, y su fraude en el conteo de los volos y en la imposición del Cnel. Mollna corno Presidente, por parte de la Asamblea Legislativa, comra el triunto real de la coalición de la Unidad Nacional Opositora (UNO), con Duarte y Ungo de candidatos a presidente y vicepresidente (Hemández Pico y otros, 1973), cerraria las puertas a cambios por mecanismos democrático-electorales, y confirmarla a diversos grupos populares en la idea de qe la única via era la revolucionaria (Montes, 1987). Pocos anos más larde, el intento del presidente Molina de realizar una "transtormación agraria", y el fracaso del intento frente a la presión del capital y sus luerzas aliadas (ECA, 1976;637643), ratificarla la creencia en los sectores más concientizados y politizados -principalmente revolucionarios y sus bases populares- de que la única via de cambios estructurales y efectivos en favor de las mayorlas populares era la revolucionaria.

Indudablemente, las condiciones materiales de vida de la población nural eran la base para cualquier movimiento reivindicativo - mucho más, revolucionario-. Sin embargo, también se dieron una serie de elementos superestructurales, o ideológicos, que coadyuvaron al proceso, y lo transformaron, de una simple presión social y reivindicativa, en un movimiento revolucionario.

Ya se ha hablado del surgimiento de los diversos grupos guerrilleros, al principio retirados de las bases campesinas y urbanas, pero en constante fortalecimiento, acercamiento, alianza y articulación. También las mismas campanas electorales, la propaganda de los partidos, especialmente el demócrata-cristiano y sus aliados de la UNO, fueron creando conciencia de la situación y espectativas de cambios, frustrados por el fraude. Asimismo, diversos grupos urbanos, principalmenle el magisterio nacional -altamente concientizado-, los estudiantes, primordialmente los de la universidad nacional, las fuerzas sindicales fueron despertando mayores grados de conciencia en el campesinado. Pero una fuerza social e ideológica tuvo un decisivo influjo en el cambio de actitudes en el campo más, y fue la iglesia católica, de la que es preciso extenderse un poco más, y por separado.

La religión -concretamente la cristiana y calólica- habia servido de elemento legilimador, no sólo de la conquista y colonia espafnola en América, sino que fue un instrumento ideológico de dominación al servicio de los sectores dominantes (Montes, 1979: 80-120). Más aún, la religión predominante - la calólica- se convirtió en sí misma en un verdadero poder que luchaba por conservarlo (Cardenal, 1980). Esta siluación, añadida a la concepción teológica predominante, proyectó hacia el campesino una mentalidad de resignación y falalismo, ante un mundo 
social injusto pero que no se podia cambiar dado que era "voluntad de Dios", trente a lo que no podia adoptar otra postura que la aceptación de esa "realidad", jumto con una actitud de sacrificio, austeridad y "moralidad", para obtener un premio eterno en recompensa.

El concilio Vaticano II, pero sobre todo la revisión y aplicación del mismo que hizo la Conferencia Episcopal de América Latina (CELAM) en Medellin, Colombia, en 1968, proyectaron una nueva concepción de la iglesia, del "pueblo de Dios", de la pastoral y de la liturgia. Se enlocó la realidad social como consecuencia de unas estructuras injustas y de un "pecado estructural", que hay que erradicar para lograr la salvación del pueblo y de la sociedad. La injusticia social ya no era algo "querido, 0 al menos permilido, por Dios", sino que era producto de una realidad histórica y de unas relaciones sociales impuestas por los hombres y los grupos de poder. La verdadera misión eclesial y cristiana era llevar la salvación a los hombres y a las estructuras, es decir, al contrario de resignarse y aceptar la situación dada, cambiar esa realidad injusta, crear unas nuevas estructuras, y asi cosntruir un "reino de justicia, de amor y de paz". Y esa es tarea no tanto de la iglesia como institución jerárquica - la que deberá promover, estimular y potenciarlo-, sino de todo cristiano y de cada comunidad, que así traerán la salvación al mundo.

Esta nueva "teologia y pastoral de la liberación" poco a poco fue siendo predicada y practicada, no sólo en los barrios populares de la ciudad, principalmente de San Salvador, donde el terreno al parecer podía estar más preparado (La te de un pueblo, 1983), sino también en amplias zonas del campo. Sacerdoles, en su mayoría jóvenes, del clero secular y regular, imbuldos del espiritu de Medellín, ceniraron su labor pasloral en esa linea y constituyeron comunidades de base inspiradas en la nueva orientación. Posiblemente el caso más conocido sea el de la zona de Aguilares, al norte del departamento de San Salvador, donde Rutilio Grande y su equipo pastoral impulsaron un nuevo modelo de trabajo misionero y de formación de comunidades cristianas, delegados de la palabra, etc. (Cardenasl, 1985). Sin embargo, por amplias y vastas zonas del campo se extendieron experiencias similares y se arraigaron nuevas comunidades cristianas. Además de las zonas populares del área metropolitana, de extracción rural en su mayoría, la nueva pasloral se fue inlroduciendo en el norte de San Salvador y de Cuscallán, en el departamenteo de Chalalenango, en Cabanas y zonas de San Vicente y La Paz, en la zona rural de Usulután, en el norte de Morazán con proyección hacia áreas colindantes de los departamentos de San Miguel y La Unión. Si se examina el mapa actual de persistencia y mayor influjo de las fuerzas insurgentes, aparece una correlación estrecha con los lugares de mayor Irabajo pastoral de liberación. 
Ya en el estudio del agro en 1980, pude percibir una evolución ideológico-politica y de organización campesina, en comparación con la primera investigación on 1973 (Montes, 1986: 175-212). Cardenal to estudia más a fondo, para el caso de Aguilares en el Análisis de la experiencia de Rutilio Grande y su equipo pastoral, abordando el proceso en todos sus aspectos (Cardenal, 1985: 247-508). Pero quien to traló en mayor profundidad desde el cambio ideológico del campesinado, sería Cabarnús, que parte de un esludio antropológico del campesinado en la zona de Aguilares y, como miembro él mismo del equipo pastoral, va estudiando el cambio operado en los campesinos, desde una mentalidad fatalista y mágica, hasta el "desbloqueo idelógico y la formación de la conciencia", que derrumba las barreras casi mágicas de interpretación tradicional y fatalista de la realidad social, para abrirse a una larea, cristiana, de translormación de esa realidad, con todas las implicaciones políticas que de ahi se derivarian (Cabarís, 1983).

b) El Climax y la crisis.

El ano de 1976 va a ser decisivo para la radicalización de las posiciones en ambos polos del espectro político. El presidente Molina logra que la Asamblea Legislativa apruebe el 29 de junio el Decrelo No. 31. o "Decreto del Primer Proyecto de Transformación Agraria"; para poderlo implementar, además de una movilización campesina, compuesta principalmente por integrantes de "ORDEN" (Organización Democrática Nacionalisla, instrumento de represión y control en el campo), por las calles de San Salvador, Irata de conseguir el apoyo de diferenles fuerzas sociales, entre ellas la iglesia calólica que desde hacia muchos anos estaba propugnando una reforma agraria.

Aparte de la verdadera voluntad política que en realidad luviera el gobierno (Montes, 1986: 147-174), el hecho tue que no pudo enfrentar la oposición cerrada de los sectores de derecha, y tuvo que renunciar al intento (ECA, 1976: 637-643; 735-772). El esperar cambios para el campesinado, a Iravés de medidas gubernamenlales, nuevamente habia fracasado. Pero, lodavía peor, las fuerzas que se impusieron al gobierno y triuntaron sobre él, buscaron en primer lugar la revancha sobre las fuerzas que se habian manifeslado a favor de la "transiormación agraria", e impusieron una línea de terror hacia las organizaciones y movimientos populares, especialmente campesinos, para prevenir cualquier resurgimiento de exigencias relormislas. La represión se llevó intensamente al campo y a los dirigentes de las organizaciones, pero también a las manifeslaciones que se movilizaban en la capital.

A comienzos de 1977 se realizarían las elecciones presidenciales, en 
las que nuevamente por medio de un fraude contra la Unidad Nacional Opositora (UNO), llegaría al poder el general Romero, abanderado de los sectores más derechistas. Las masas concentradas en el parque Libertad, en protesta por el fraude electoral, serian finalmente masacradas, surgiendo en reacción las "Ligas Populares, 28 de febrero" (LP 28). Se cerraba con ello la última esperranza y la última alternaliva de cambios por medio de procesos democráticos. Como consecuencia, se comienza a militarizar el campo, para "prevenir" pósibles alzamiento y movimientos "subversivos", se intesifica la represión, amparándose para ello en la suspensión de garantias constitucionales, o "estado de sitio" (Ungo, 1977: 359-366).

La iglesia calólica, que por un lado era vista como agente concientizador del campesinado, y por olro lado se habia pronunciado parcialmente a favor de la "transformación agraria", seria también uno de los locos de represión: el 12 der marzo de 1977 serla asesinado el sacerdote jesuita Rulilio Grande, párroco de Aguilares, junto con dos laicos acompananles, cuando se dirigia a oficiar la misa en El Paisnal; la utherior toma de la ciudad de Aguilares, represión de la población y la expulsión del país del equipo de pasloral en mayo del mismo año (Cardenal, 1985: 543-600) ; seguiría el asesinato del P. Navarro, párroco de la colonia Miramonte en San Salvador; se publicaban lemas como el de "Haz patria, mala a un cura", los escuadrones de la muerle dieron un ultimalun a los jesuílas, a mediados del ano, diciendo que abandonaran el pais en el plazo de un mes, o que serian asesinados uno por uno, frente a lo que los jesuitas decidieron quedarse y correr el riesgo del pueblo perseguido, publicando en los medios de comunicación una serie de escritos en que juslificban su opción (ECA, 1977: 434-450). Seguiria la represión más cruel conlra el pueblo y sus dirigentes, la violación sistemática de los derechos humanos, que culminaria con el asesinato de Mons. Oscar Arnulio Romero, arzobispo de San Salvador, el 24 de marzo de 1980, mientras celebraba la misa; el de otros diez sacerdoles en dicho periodo; concluyendo con el asesinato de cuatro misioneras norteamericanas, el rector de la Universidad de El Salvador, y los dirigentes del Frente Democrático Revolucionario (FDR) al finalizar el año 1980 (ECA, 1980: 925-926, 1211-1219).

El 15 de oclubre de 1979 se produjo un golpe militar, liderado por oficiales jóvenes, que se proponian cambiar la siluación del pais, introducir cambios y reformas, y garantizar la vigencia de los derechos humanos (ECA, 1979: 849-1033); pero seria cooptado por jeles militares superiores y por luerzas sociales contrarias a la "PROCLAMA DE LA FUERZA ARMADA" (ECA, 1980: 5-20, 117-141).

Sin embargo, desde el mismo momento del golpe las organizaciones revolucionarias y las populares lo denunciaron como una maniobra para 
cambiar la imagen, y para impedir el triunto revolucionario tras el éxito del sandinismo en Nicaragua (ECA, 1979: 1021-1031; 1980: 128-135).

En este contexto se va a aprobar y a impulsar la relorma agraria, que llegaria larde para "arrebalar banderas" a los movimientos campesinos e insurgentes, pero que posibilitaria la mililarización y férreo control en el campo (Montes, 1986: 240-252), o para contener el movimiento insurgente ya consolidado; al mismo tiempo que conseguiría magros frutos en lodos sus aspectos (Montes, 1986b: 240-256; Studemeister, 1986). No se puede entender la reforma agraria como un voluntarismo de los nuevos grupos en el poder, sino como resultado de las presiones de organizaciones campesinas y populares, asi como de los grupos guerrilleros, que dieron paso a una nueva correlación de fuerzas, y como consecuencia se adoplarían lales medidas por el temor de un inminente triunto revolucionario.

El papel que desempeñaría la iglesia calólica en lodo este contexto fue de una relevancia increíble. Mons. Romero había sido propuesto para arzobispo de San Salvador por los grupos más derechistas, contra la candidatura de Mons. Rivera, bien visto por los sectores más abierlos y progresislas; pero el asesinato de Rulilo Grande le abrió los ojos, para ponerse cada día más del lado del pueblo, iniciando una serie de gestos proféticos, como la misa única el domingo siguiente al asesinato de Rutilio, la negativa a asistir a la toma de posesión del general Romero como Presidente, por no haberse esclarecido los asesinatos de los dos sacerdotes (Cardenal, 1985: 584-600), hasta convertirse en el lider indisculible y el denunciador de toda opresión y represión, considerado como "la voz de los sin voz" (Brockman, 1985; Montgomery, 1982, entre muchos otros). Los diez sacerdotes asesinados además del arzobispo Romero, las religiosas martirizadas, los innumerables calequistas, delegados de la palabra y colaboradores eclesiales que ofrendaron su vida por ello, el numeroso grupo de sacerdoles y religiosas que luvieron que abandonar el país, o que se vieron impedidos de regresar, son testimonio fehaciente de lo que significaba el elemento religioso en el proceso, por lo que lenia que ser eliminado o intimidado a la hora de implementar una guerra de contrainsurgencia contra el pueblo (LA IGLESIA EN EL SALVADOR, 1982). El carisma -más que la instituciónque habia inspirado y abierto los ojos al pueblo y al campesinado, no sólo no podia dejar abandonado a ese pueblo, sino que seria una victima cualificada en la represión, que pretendia privar al movimiento campesino e insurgente de sus inspiradores en una de las dimensiones más importantes de su mentalidad y concepcićn del mundo. Una gran parte de los sacerdoles, religiosas y laicos más comprometidos con el pueblo y con el proceso - de los que sería la mayor parte de víctimas y exiliadosconstituyeron la Coordinadora Nacional de la Iglesia Popular (CONIP), 
que no prelendia ser una iglesia paralela, sino unir y coordinar el trabajo de los más conscientes del problema y de los más identificados con el pueblo y su sulrimiento.

c) La guerra civil.

Las organizaciones populares, campesinas y urbanas, crecían en número, en consolidacion organizativa y en niveles de conciencia y combatividad. El dia 22 de enero de 1980 la recientemente conslituida "Coordinadona Nacional" (CN), integrada por las organizaciones populares, realiza en las calles de San Salvador la mayor concentración y manilestación de la historia del país, con una movilización de más de doscientas mil personas -y la presencia simpatizante de miles de observadores a su paso-, que seria ametrallada por las fuerzas armadas y de seguridad, dejando un elevado saldo de muertos y heridos en las calles de la capital (ECA, 1980: 101-108).

A mi modo de ver, el 22 de enero fue un momento crucial con el proceso revolucionario y contrarrevolucionario salvadorefio. Por un lado, las organizaciones populares y las guerrilleras tomaron conciencia vivencial de su fuerza, de la magnitud de sus bases, y de la simpatia de que gozaban en la población. Por otro lado, el régimen también tomó conciencia de la magnitud del movimiento popular e insurgente, de la amenaza que contituia para su proyecto y del peligro inminente de un posible triunlo popular-revolucionario. Frente a semejante amenaza no le quedaba más alternativa que entrentarlo militarmente, reprimirlo, implantar un régimen de terror y asi hacerle frente antes de que se consolidara todavía más. Para el movimiento popular y revolucionario, por el contrario, la reacción del régimen les aclaraba que no había posibilidad alguna de lucha popular pacífica, y que habia que militarizarse, prepararse para una larga lucha, y emprender el camino de la revolución armada. El asesinato de Mons. Romero, la masacre en su entierro, no harian sino contirmar lal percepción y decisión política.

La crisis orgánica que haria eclosión en el golpe del 15 de octubre de 1979, que se intentó resolver $\longrightarrow$, al menos, paliar - con las sucesivos cambios y reacomodos, se desataria de forma lolal, y por el momento irresoluta, a lo largo de 1980 para desarrollarse abientamente a partir de la "olensiva final" lanzada por el "Frente Farabundo Marti para la Liberación Nacional" (FMLN), el día 10 de enero de 198I: 70-74), con el apoyo del "Frente Democrático Revolucionario" (FDR), vinculado orgánicamente con el anterior; desde ese momento, no sólo se libra la guerra civil, sino que se polarizan las fuerzas sociales, en apoyo de cada uno de los bloques y proyectos opuestos (Montes, 1984: 13-35, 59166).

La guerra civil, desalada lormalmente el 10 de enero de 1981, lleva ya siete anos y medio de duración, sin que se prevea un final en el hori- 
zonte, por la victoria militar de ninguna de las parles. El optimismo manifestado por el gobierno, la instilución armada, e incluso por voceros de la embajada norleamericana, se ha vislo nublado con el alaque al cuartel del Paraiso, Chalatenango, el último día del mes de marzo de 1987, y por las continuas acciones olensivas contra posiciones del ejércilo desde esa fecha hasta el momento; a tal punlo que voceros de la misma embajada han soslenido que la guerra podrá durar lodavía de seis a ocho años más. Los intentos de diálogo-negociación entre ambas partes contendientes no han avanzado significalivamente, de modo que tampoco se vislumbra una alternativa de solución polílica.

Sobre al guerra civil salvadorefia son muchos los trabajos que se han publicado. Además de los ya citados, es indispensable un seguimiento de lo que ha ido publicando la revista ECA en eslos afios, así como el semanario PROCESO, CARTA A LAS IGLESIAS, y otras publicaciones de la UCA. Más específicamente abordan la crisis y la guerra en EI Salvador: Armstrong y Rubin (1983), Baloyra (1984), Lungo (1986). Sin embargo, hay dos obras fundamentales para entender la guerra civil salvadorefía desde dentro mismo del campo revolucionario, asi como para comprender el complejo fenómeno de la insurgencia, sus motivaciones y el proceso mismo vivido día a día; el alto componente campesino del movimiento, asi como el contenido religioso motivacional de muchos de sus integrantes, a partir de las mismas comunidades de base y de la nueva pastoral implemenlada en las zonas en que la guerrilla tiene mayor presencia y raigambre: Clemenls, 1986; y López Vigil, 1987. Si bien es cierto que tanto en la dirigencia de la organización insurgente en los cuadros intermedios y on las bases, hay elementos de extracción urbana, universitaria e intelectual, la mayoría de sus inlegrantes proceden del sector rural y campesino, principalmente en las dos agnupaciones más numerosas y más conocidas al inlerior del pais para algunos sectores: las Fuerzas Populares de Liberación (FPL) y el Ejército Revolucionario del Pueblo (ERP); e incluso a los cuadros intermedios y a la cupula misma han accedido algunos miembros provenientes de la base campesina.

No solo son los campesinos los mayores componentes de los movimientos insurreccionales salvadorefíos acluales, sino que también lo son en cuanlo a que aportan el mayor número de victimas de la guerra, en ambos bandos, ya que el servicio militar no se ha podido hacer obligatorio, ni siquiera en tiempo de guerra, para toda la población sin distinción de clase o extracción (ctr.: Socorro Jurídico Cristiano, Tutela Legal del Arzobispado, Comisión no-gubemamental de Derechos Humanos, etc.: Informes anuales; IDHUCA, Fasciculo II, 1986, Fascículo IV,1987). Los dos esludios que hemos realizado sobre los desplazados y refugiados salvadorefios por causa de la violencia y de la guerra claramente evidencia que los desplazados en el interior del país -así como una 
buena parte de los refugiados en el área centroamericana, principalmente en Honduras y Nicaragua - son campesinos de los más pobres, ubicados en las zonas más atrasadas y abandonadas del país, que han tenido que abandonar sus escasas pertenencias y los sobrevivientes encontrar lugares de mayor seguridad, esperando poder regresar a sus sitios de origen para continuar Irabajando la tierra, y mientras tanto pretenden seguir cultivando el campo o buscar otras ocupaciones fundamentalmente rurales (INSTITUTO, 1985; 1986). Pero incluso entre los que han emigrado hacia los Estados Unidos-tenómeno igualmenle motivado por la violencia y la guerra-, un elevado porcentaje también era de extracción rural y campesina, que ha huido y buscado refugio por razones similares (INSTITUTO, 1987).

Por lo que se refiere al componente religioso en las tilas insurgentes, ya se ha sustentado básicamente en los apartados anteriores, por lo que respecta a su origen, motivaciones y otros elementos. Indudablemente el mismo proceso va "secularizando" el movimienlo. La formación política se va imponiendo sobre cualquier otra motivación ideológica. Sin embargo, en las zonas controladas o de mayor persistencia de la guerrilla continúa habiendo actividad religiosa, con no sólo tolerancia sino respeto e incluso apoyo de la dirigencia insurrecional. Las actividades pastorales son permanentes, asl como los actos rituales o de culto, muchas veces presididos y dirigidos por los propios agentes de pastoral que están con la guerrila. La demanda de material religioso, de formación, motivación y charlas es constante, $\theta$ incluso solicitado por la dirigencia, en profunda comprensión del componente religioso del campesinado salvadoreho y de sus cuadros y bases. La presencia de sacerdotes y religiosas no sólo es tolerada, sino que desde casi el comienzo de la guerra civil varios sacerdoles, que han optado por acompanar al pueblo y a la guerrila en todo el proceso, se movilizan con las luerzas insurgentes en una acción puramente pastoral bien vista y querida por la comandancia del FMLN (López Vigil, 1987). Por otro lado, si bien la iglesia institucional no brinda el mismo apoyo al movimiento, como en tiempos de Mons. Romero, el arzobispo de San Salvador, Mons. Rivera y Damas, no sólo goza del respeto de los insurgentes, sino que es una pieza clave como mediador en cualquier negociación parcial (canje de prisioneros, liberación de lisiados para que salgan del pais a curarse, intercambio para la liberación de la hija del presidente Duarte), o en cualquier paso o negociación en todo proceso de diálogo hasta el momerto.

\section{Categorización de los levantamlentos campesinos en El Salvador.}

Ya en la misma descripción narrativa que he venido haciendo de los diversos movimientos, levantamiento y/o revoluciones campesinas en El 
Salvador se perciben diferencias muy signiticativas entre ellos, y muy marcadamente entre los anteriores y la que todavia esta por resolverse. Pero creo que convienen intentar algún lipo de categorización que explique esas diferencias, así como los resullados que se derivaron de ellas, para poder entender la aclual revolución y guerra civil y por qué no ha sido vencida en pocos dias como los anteriores.

\section{A. Elemento material subyacenle.}

No se puede negar que hay un elemento malerial subyacente en todo movimiento campesino -concrelamenle en el salvadorefio-, y es el empeoramiemto de sus condiciones de vida, de modo que cuando no pueden reproducir su fuerza de trabajo y su vida social, buscan soluciones reivindicativas que les posibiliten esas metas minimas. Cuando ese elemento material se vuelve insoportable, puede surgir un levantamiento.

El caso de los nonualcos liderados por Anaslasio Aquino, es uno de esos limites en que la situación material se vuelve insoportable para la población de la zona; si en otras regiones del pals la siluación económica no era más bonancible, tal vez no la consideraban desesperada -aparte de que posiblemente no se dieron otros elementos coadyuvantes e imprescindible, como serían el liderazgo y algún otro aglutinante ideológico o étnico.

En 1932 será el occidente del pais, monopolista gran parte de la tierra por el cultivo del café, el que sulrirá las condiciones de vida más intolerables, incapaces de satisfacer sus necesidades minimas o de reproducir su vida y tuerza de trabajo; debido a la crisis mundial, la caida en picada de los precios del calé, el subsiguiente desempleo o la retribución con salarios menores que de hambre. A ello se uniria el movimienlo indigena de los izalcos, en la misma zona, liderados por José Feliciano Ama, a quienes se habla privado de sus propiedades comunales y de las cofradias por la reforma agrarla de 1881-82 deteriorándoles con ello sus condiciones materiales de vida - agudizadas también por la crisis mundia- y se les habla prácticamente eliminado la capacidad de una mínima autonomía cultural, social y política, como ya se ha indicado (Dalton, 1972). Sin embargo, es preciso notar que los indígenas de la zona, en su mayorla tenlan tierras de cultivo, parcelas de mucha lecundidad, y que el colapso de calé no delerioró sus condiciones de vida en la misma proporción que a los ladinos y campesinos de las zonas exclusivamente cafetaleras, por lo que el levantamiento de 1932 tiene un fuerte componente indigena que no era estrictamente material y económico. En el resto del pais, por el contrario, el campesinado no sulrió el mismo impacto de la crisis, pues la quiebra del anil, como se ha indicado, abrio la posibilidad de acceso a tierras para el cullivo y producción de granos 
básicos y de subsislencia; aunque las condiciones de reproducción de su vida fueran precarias, no llegaban a ser desesperadas, como para levantarse en armas con todas las consecuencias que se podian prever. El que los nonualcos no se unieron no fue tanto por el escarmiento de un siglo atrás, sino porque sus condiciones de vida no eran desesperadas.

En la crisis actual, por el contrario, como ya se ha indicado más arriba, el problema no está localizado en pequenas zonas del país. El avance del proceso capilalista en la agricultura, el haber alcanzado la frontera agrícola y haber destinado las tierras en cierto sentido "ociosas" a la producción intensiva del algodón y la cana, relegando al campesinado a las tierras marginales, y privándolo de trabajo permanente, de tierras de subsistencia y de ingresos minimos, crearon las condiciones amplias y muy generalizadas de imposibilidad de reproducir su vida y su fuerza de trabajo. La mayor concentración de pobreza en las zonas de mayor presencia y luego control o persistencia guerrillera tiene que tener una correlación explicativa; así como el que la participación y presencia insurgente sea menor o casi nula en las anteriores regiones de levantamiento -nonualcos e izalcos, si bien en los primeros con el curso de la guerra civil se ha dado mayor presencia - no tanto por el escarmiento producido en las respeclivas represiones, cuanto porque en esos lugares el trabajo y la posibilidad de reproducir su vida no ha alcanzado los límites de intolerabilidad deseperada.

\section{B. Elememo ideológico sustemtante.}

El que las condiciones maleriales sean tales que la población no pueda reproducir su fuerza de trabajo ni su vida social, es un requisito indispensable para cualquier movimienlo insurreccional. Sin embargo, es indispensable lambién algún componente ideológico para que la acción se convierta en algo más que simple protesta, o en reacciones esponlaneistas, individuales y/o grupales, o en simples acciones reivindicalivas, a veces desesperadas, y se transforme en levantamientos 0 , mucho más aún, en revoluciones. Este elemento ideologico es el que, a mi juicio, establece las diferencias cualitativas en los movimiento campesinos salvadorenos.

\section{a) Levantamienlos campesinos (1833 y 1932).}

Tanto el levantamiento campesino liderado por Aquino (1833) entre los nonualcos, como el liderado por Ama (1932) y otros ladinos en el occidenle del pais en la zona de los izalcos, tenian un componente ideológico muy débil. Sus demandas eran casi exclusivamente económicas y reivindicativas, aunque percibieran de algún modo la necesidad de un modelo diferemte de sociedad y de unas relaciones sociales distintas. 
Carecian de componentes ideológicos aglutinantes que propiciaran la solidaridad y apoyo de otros grupos sociales $y$ engendraran un movimiento más amplio, con alianzas de grupos externos, principalmente no campesinos y urbanos. Carecian sobre todo, de una ideología revolucionaria y de un proyecto socio-politico alternativo. Si este aspecto es claro en el movimiento de los nonualcos, también lo es básicamente para el del occidente del país en 1932 (izalcos), de acuerdo a lo que reconoce el dirigente comunista Miguel Mármol en cuanto a la incapacidad del partido de dirigir $e$ incluso controlar el movimiento y los alzamientos espontaneistas (Dalton, 1972).

El componente ideológico más manitiesto, como era el étnico -excusivo para el caso de los nonualcos, y uno de los más tuertes en el de los izalcos-, más bien era un comonente aislante del reslo de la sociedad. Para ese entonces los indígenas eran una muy pequena minoria en El Salvador, aislada y localizada, menospreciada por el resto de la sociedad y por los valores dominantes desde la conquisla y colonia, e incluso no provocaba una alianza y solidaridad entre los diversos grupos indigenas del país o del área, por las diferencias establecidas y las rivalidades históricas o los aislamientos seculares. Por su parte, la religión y su orientación prevaleciente en la época elemento ideológico importante, sobre lodo en el campesinado- no sólo no era favorable a movimientos reivindicativos de esa índole, sino que le era hostil.

El que los alzamientos de 1833 y 1932 fueran focalizado y no lograran la unidad del campesinado y de las clases empobrecidas de las ciudades, no se debio exclusivamenle, ni en gran medida, a que en el resto del país las condiciones materiales no tueran desesperadas - para muchos si lo eran-, cuanto al hecho de que se carecla de un elemento ideológico capaz de motivar a olros grupos, regiones y sectores; más bien, el elemenlo étnico era un aislante para que se adhirieran olros seclores no indigenas. Tampoco tenía ninguno de los dos alzamientos una teoría revolucionaria ni proyeclos alternalivos, por lo que sus movimientos se reducian al espontaneísmo organizado y liderado, o a alzamienlos reivindicativos focalizados.

b) La revolución campesina (1981-1987).

El movimiento insurgente que se desato en forma de guerra civil formal en enero de 1981, por el contrario, lienen unos componentes tales que Irascienden la categoria de "alzamientos", para convertirse en una verdadera "revolución". Ya no se trala lanto de damandas reivindicativas, cuanto de exigencia violenta de cambios estructurales, de la implantación de un nuevo sistema, el socialista.

Es cierto, como se ha expresado antes, que las condiciones mate- 
riales se han deteriorado a niveles insoportables en extensiones de terreno y de población, a lo largo y ancho del territorio nacional, especialmente en las zonas en que la tierra es de peor calidad y los campesinos han sido relegados a las franjas improduclivas, asl como en vastas zonas marginales y de miseria en las ciudades, especialmemte en el área metropolitana de San Salvador. Pero a ello se ha unido un alto componente ideológico más universal, y una teorla revolucionaria, que ha propiciado la alianza de intelectuales, obreros y campesinos hacia un nuevo proyecto de sociedad.

Los grupos guerrilleros, compuestos en su mayoría por "intelectuales" y algunos dirigentes obreros, disponian desde su formación de un fuerte componente ideológico, más universal, y de una teoría revolucionaria. No se trataba, por lo lanlo, de una motivación étnica -consiguientemente excluyente, focalizada-, sino que estaba fundamentada en condiciones de clase social o de alianzas de clases. Amplios sectores del campesinado, como ya se ha indicado, se unieron en movimientos al comienzo reivindicativos, aunque con una mayor apertura ideológica propiciada por la nueva interpretación teológica y praxis pasloral, pero la represión de que lueron objeto los condujo a una alianza primero táctica y luego estratégica con los grupos guerrilleros (Cabamús, 1983; Cardenal, 1985), para más tarde eslablecer una vinculación orgánica que pudiera dar paso a la revolución (Montes, 1984: 28-34). Algo similar ocurrirla con los sectores obreros y marginales ubanos (LA FE DE UN PUEBLO, 1983; López vigil, 1987).

El componente ideológico, por 10 tanto, es un èlemento fundamental en el proceso salvadorefio actual, sulicientemente amplio y universal como para que sea incorporado por diversos seclores, grupos y clases, trascendiendo etnias, subideologias e intereses parciales. $Y$ aunque no sea un movimienlo puramente campesino, ese sector es el predominante, no sólo en número sino lambién en muchos componentes de la ideología y del proyecto nacional revolucionario. El que amplios sectores de la iglesia católica hayan optado por la teología y pastoral de la liberación ha propiciado y polenciado el paso del campesino de una mentalidad puramente reivindicativa a una apertura ideológica que le posibilitara su inlegración al movimiento revolucionario. Por su parte, la pastoral en algunas zonas urbanas y, sobre todo, el liderazgo y compromiso de Mons. Romero, abrieron nuevos horizontes ideológicos en olros sectores, principalmente urbanos -además del campesinado-, laborales e intelectuales, que viabilizaron la alianza y la vinculación orgánica más universal hacia un nuevo proyecto.

Por último, a diferencia de los alzamientos campesino anteriores, el movimiento revolucionario actual tiene una teoria revolucionaria y un proyecto socio-político distinto. Se podrá estar o no de acuerdo con el 
mismo, pero es una realidad objeliva incuestionable. Aunque los distintos sectores integrantes del mismo no lo tuvieran, o no $10 \mathrm{com}-$ partieran por igual desde el inicio, no impide el que to hayan ido asimilando e inlegrando a to largo de la lucha, y hoy no sólo una alianza estratégica, sino una vinculación orgánica entre todos sus participantes. El sector campesino, en un inicio, lenia más bien una actitud reivindicaliva, pero las mismas condiciones le impusieron una radicalización creciente, hasla tormar parte del todo revolucionario y concebir el futuro dentro de un cambio para toda la sociedad; aunque para el campesinado, en un comienzo, el modelo socialista no sea su ideal, sin embargo, entra en una alianza de clases con obreros e intelectuales - hegemonizada por los dos últimos- no sólo porque la represión necesariamente los une, sino porque son conscientes de que el sistema capilalisla es incapaz de crear las condiciones para la reproducción de la economía campesina ni de generar puestos de trabajo suflcientes. Las alianzas, por otro lado, implican concesiones muluas para un objetivo común; esto supone concesiones y avances de ambas partes, concretamente una mayor apertura y ampliación de horizonles y objetivos del campesinado en aras del proyecto revolucionario, asi como una mayor asimilación e incorporación en el mismo de las exigencias y caraclerísticas campesinas, tanto al interior de la organización, como del proyecto de nación. Esas características campesinas incorporadas serán, principalmente, la vinculación con la tierra, la lucha por la tierra, la dureza y austeridad de vida, de trabajo y de lucha, de cosmovisión campesina de identificación con la naluraleza como parte de la misma, lo que alimenta su profunda religiosidad popular.

El más amplio y abierto contenido ideológico, así como el que exista una ideologia revolucionaria, hace que el movimiento no sea élnico ni de una sola clase social eslrictamente considerada, ni que está focalizado en reducidas zonas, sino que sea más extenso, y casi nacional; asímismo, hace que no sea aislado y aniquilado rápidamente por las fuerzas armadas gubernamentales, sino que perdure por tan largo liempo, e incluso que se extiende por nuevas zonas del territorio nacional, incorporando nuevas áreas y grupos sociales al movimiento, y amenazando con un triunfo revolucionario si es que los Estados Unidos no continúan con la misma o creciente ayuda militar, económica y política.

\section{A modo de conclusión.}

La tierra en El Salvador, $\infty$ mo se ha descrito en mis anleriores trabajos que fundamentan a éste, es el recurso natural prácticamenle exclusivo, lo que la convierte en objeto de compelencia por poseerla, y las relaciones económicas y sociales vinculadas con la tierra llevan aparejadas convulsiones sociales y políticas, que se van repitiendo más o menos perio- 
dicamente, con diferentes carácterísticas, motivaciones y componentes sociales.

A lo largo de la historia, desde la conquisla y colonia, pero sobre lodo desde la independiencia, primero centroamericana y luego nacional, ha habido una serie de movimientos campesinos, de los que los más importanles han sido los de 1833, 1932 y el presente. Sin embargo. existen o se perciben diferencias muy claras entre los dos primeros y el último, que explican su proceso y desenlace.

En todos ellos ha habido un elemenlo material imprescindible, que son las condiciones económicas y la imposibilidad de reproducir su fuerza de trabajo y sı vida social. Sin embargo, el elemento ideológico que lo acompaña ha sido cualitativamente distinto. Mientras en los dos primeros movimientos campesinos se carecía de una ideología amplia y de una teoría revolucionaria, que pudiera aglutinar a diversos sectores sociales y ampliarse a zonas extensas del terrilorio nacional -por el contrario, el componente élnico lo restringia y focalizaba-; el movimiento actual no es exclusivamente campesino, sino que se basa en una amplia alianza de clases pobres y en una estruclura y vinculación orgánica, en torno a una ideología más universal y con un proyecto socio-político y una teoria revolucionaria que lo sustenta. Además, el faclor religioso, fuertemente presente en el campesinado e incluso en amplios sectores ubanos en su mayoria de recienle migración y extracción rural-, ha incidido de muy distinta manera en los primeros y en el actual.

Del análisis de los procesos y movimientos estudiados se puede concluir que alzarnientos campesinos que estén focalizados y carezcan de una ideologia más amplia y de una teoría y proyecto revolucionarios -más aún si lienen un fuerle componente élnico indigena-, están llamados al aislamiento y consiguiente fracaso, con masacres de su población por la concentración de luerzas armadas gubemamentales que lo aniquilan en breve tiempo. En cambio, movimientos campesinos, abiertos a una alianza amplia con otros sectores sociales, por haber adoptado una ideología más universal y tener o asimilar teorias revolucionarias y proyectos socio-polílicos nacionales, y no restringidos a sus intereses particulares, tienen mayores posibilidades de triunfo, en la medida en que la coyuntura lo permita, y en la medida en que no haya alianzas del régimen con potencias extemas para combatirlo. Sin embargo, a pesar de todo el esfuerzo gubernamental, $y$ de la ingente ayuda exlema que recibe, no ha podido derrotar al movimiento insurgente, ni se prevé que pueda derrotarlo en un largo período, manteniéndose sustancialmente igual la correlación de fuerzas y el apoyo externo. El caso salvadorefio ofrece elementos para revisar las leorias revolucionarias y conlrarrevolucionarias, por la duración de la crisis orgánica y de la guerra civil subsiguienle, por las condiciones adversas de la topografía y de la población 
asenlada, por la capacidad de abastecimiento sin una retaguardia asegurada -y menos aún, internacional, dada la presencia norteamericana en Honduras, y la permanente vigilancia aérea. El fuluro de la revolución salvadorena es incierto, pero es claro que no ha sido derrotada, ni mucho menos; más bien, se han ido alcanzado metas en olro tiempo inconcebibles, como la relorma agraria -por deficiente e ineficaz que sea, y que no haya beneficiado ni a la mayoria del campesinada, ni muchos menos a los miembros de organizaciones por cuya presión se implementó-, o como la aceplación "de facto" del FMLN y el imlento repetido de dialogar y negociar algunos puntos concrelos.

\section{BIBLIOGRAFIA UTILIZADA.}

ANDERSON, Thomas; EL SALVADOR. Los sucesos politicos de 1932; San José. EDUCA. 1976.

ARIAS GOMEZ, Jorge; 'Anastasio Aquino, recuerdo, valoración y presencia", en rev. LA UNIVERDIOAD, revista Trimestral de la Universidad de El Salvador, enero-junio 1964, Nos. 1-2, Año LXXXIX; Editorial Universitaria, San Salvador, págs. 61-112.

ARMSTRONG, Robert y RUBIN, Janet S.; EL SALVADOR; EL ROSTRO DE LA AEVOLUCION; San Salvador, UCA editores, 1983.

BALOYRA, Enrique; EL SALVADOR EN TRANSICION; San Salvador, UCA editbres, 1984.

BROCKMAN, James R.; LA PALABPA OUEDA. Vida de Mons. Oscer A. Romero, San Salvador, UCA editores, 1985.

CABARRUS, Cartos R.; GENESIS DE UNA REVOLUCION; México ediciones de la casa chata, 1983.

CARDENAL, Rodolfo; EL PODER ECLESIASTICO EN EL SALVADOR; San Salvador, UCA editores, 1980.

HISTORIA DE UNA ESPERANZA. Vida de Rutilio Grande; San Salvador, UCA editores, 1985.

CARTA A LAS IGLESIAS; Publicación quincenal del Servicio informativo del Centro de Pastoral de la UCA, San Salvador.

CLEMENTS, Charles; GUAZAPA. Testimonio de guerta de un médico norteamericano; San Salvador, UCA editores, 1986 (1a).

DALTON, Roque; MIGUEL MARMOL. Los sucesos de 1932 en El Salvador; San José, EDUCA, 1972.

ECA: ESTUDIOS CENTROAMERICANOS. Revista de extensión cultural de la Universidad Centroamericana José Simeón Cañas (UCA), San Salvador: ¿QQué pasó en la Cayetana?" (Vida Nacional); nov.-dic. 1974, 804-806."EL Salvador se conmueve" (Editorial); julio 1975, 325-328. "A sus órdenes, mi capital" (Editorial); nov. 1976, 637. 643. "Las relormas a la Ley del ISTA y del Primer Proyecto de Transformación Agraria"; ibidem, 735-746. "La transtormación de la ley del ISTA' (Ignacio Ellacurla); ibidem. 747. 758."De la Transtormacción Agraria a la delensa del latifundio" (Luis de Sebastián); ibidem, 759-772. "Los jesultas ante el pueblo salvadoreño"; junio 1977, 434-450. "AquI, El Salvador. La insurreción militar del 15 de octubre de 1979 y sus consecuencias sociales" (No. monográfico); oct.-nov. 1979, 849-1033. "In Memorian del Ing. Félix Antonio Ulloa, Rector de la Universidad de El Salvador (Editorial); oct.-nov. 1980, 925 926. "La represión desesperada" (Documentación); dic. 1980, 1211-1219. "Pronunciamiento de la UCA ante la nueva situación del pals (tebrero/80)" (Editorial); en.-leb. 1980, 5-20. "Crónica del mes. Enero 1980"; en.-leb. 1980, 101-108. "Documentación"; ibidem, 117-141. "Crónica del mes. Enero 1981; en.-leb. 1981, 70-74. 
HERNANDEZ PICO, Juan, y otros; EL SALVADOR; AÑO POLITICO 1971-72; San Salvador. UCA, 1973.

IDHUCA: INSTITUTO DE DERECHOS HUMANOS DE LA UCA; Fasclaulo II: LOS DERECHOS HUMANOS EN EL SALVADOR DURANTE EL AÑO 1985; San Salvador, UCA, 1986. FasclculoIV: LOSDERECHOS HUMANOSEN ELSALVADORDURANTE EL AÑO 1986; San Salvador, UCA, 1987.

INSTITUTO DE INVESTIGACIONES; EL SALVADOR 1985: DESPLAZADOS $Y$ REFUGIADOS; San Salvador. UCA, 1985.

EL SALVADOR 1986: EN BUSCA DE SOLUCIONES PARA LOS DESPLAZADOS; San Salvador, UCA, 1986.

EL SALVADOR 1987: LOS SALVADOREÑOS REFUGIADOS EN LOS ESTADOS UNIDOS: (Segundo Montes), San Salvador, UCA. 1987.

LA FE DE UN PUEBLO. Historia de una comunidad eristiana en EL Salvador; San Salvador, UCA editores. 1983.

LA IGLESIA EN EL SALVADOR: San Salvador, UCA editores, 1982 (2a.).

LOPEZ VIGIL, Marla; MUERTE Y VIDA EN MORAZAN, Testimonio de un sacerdote; San Salvador, UCA editores, 1987.

LUNGO, Mario: EL SALVADOR 1981-1984. Laldimensión polltica de la guerra; San Salvador, UCA editores, 1986.

MONTES, Segundo; EL COMPADRAZGO. Una estuuctura de poder en El Salvador; San Salvador, UCA editores, 1979 (1a).

ESTUDIO SOBRE ESTRATIFICACION SOCIAL EN EL SALVADOR; San Salvador, UCA, 1979a.

EL SALVADOR ; LAS FUERZZAS SOCIALES EN LA PRESENTE COYUNTURA (enero 1980 a diciembre 1983); San Selvador, UCA 1984.

EL AGRO SALVADOREÑO (1973-1980); San Salvador, UCA editores, 1986."

EI Salvador: une nation sans Indiens?"; en rev.

ETHNIES, droits de 1 "home et peuples autochtones, Paris, éte-automne 1986, 4-5, págs. 29-30.

"El Salvador: la tierra, epicentro de la crisis"; en BOLETIN de ciencias económies y sociales; San Salvador, UCA, julio-agosto 1986a, págs. 240-256.

"Los IImites y posibilidades que enlrenta la particpación polltica en el campo salvadoreño"; en rev. ECA, mayo-junio 1987, págs. 305-322.

MONTGOMERY, Tommie Sue; REVOLUTION EN EL SALVAOOR. Origins and Evolutión; Boulder, Coloredo, Westview Press, Inc., 1982.

PROCESO; Inlormativo semanal: San Salvador, UCA, Centro Universitario de Documentación e Intormación.

STUDEMEISTER, Margarita Sandra; SOCIAL CONFLICT AND THE 1980 AGRARIAN REFORM IN EL SALVADOR. A thesis submitted to the faculty of San Francisco State University in partial hulfillment of the requeriments tor the degree of Master of Arts in Social Sciences: Interdisciplinary Studies: San Francisco, Calilornia, 1986 (mimeo).

UNGO, Guillermo Manuel; "La suspensión de garantlas constitucionales en El Salvador; on rev. ECA. junio 1977, págs 359-366. 